Article

\title{
An Experimental Study on the Thermal Performance of Phase-Change Material and Wood-Plastic Composites for Building Roofs
}

\author{
Min Hee Chung * and Jin Chul Park \\ School of Architecture and Building Science, Chung-Ang University, Seoul 06974, Korea; jincpark@cau.ac.kr \\ * Correspondence: mhloveu@cau.ac.kr; Tel.: +82-2-823-2221 \\ Academic Editor: Chi-Ming Lai \\ Received: 25 November 2016; Accepted: 5 February 2017; Published: 10 February 2017
}

\begin{abstract}
We assessed the usefulness of phase-change material (PCM)-based thermal plates fabricated from wood-plastic composites (WPCs) in mitigating the urban heat island effect. The thermal performance of plates containing PCMs with two different melting temperatures and with two different albedo levels was evaluated. The results showed that the PCM with a melting temperature of $44^{\circ} \mathrm{C}$ maintained lower surface and inner temperatures than the PCM with a melting temperature of $25^{\circ} \mathrm{C}$. Moreover, a higher surface albedo resulted in a lower surface temperature. However, the thermal performance of PCMs with different melting temperatures but the same surface albedo did not differ. Using PCM-based materials in roof finishing materials can reduce surface temperatures and improve thermal comfort.
\end{abstract}

Keywords: roof temperature; phase-change materials; wood-plastic composite (WPC)

\section{Introduction}

Recently, the use of phase-change materials (PCMs) in building components, such as walls [1-3], roofs [4-10], windows [11-13], and floors [14-17], has grown. PCMs function as thermal storage materials that can absorb or release heat during liquefaction or solidification at their phase-change temperatures. PCMs can help in maintaining a relatively constant temperature, depending on the climate and the purpose of the application. The use of PCMs can help to reduce energy demands and improve indoor thermal comfort.

PCM roofs are effective in improving indoor environments. Several PCM-based methods of roof construction have been proposed to reduce surface temperatures and building energy consumption. Guichard et al. [4] investigated the thermal behavior of building roofs with and without PCM layers in a tropical and humid climate and proposed a roof equipped with plasterboard and PCM-finished dark corrugated iron. They reported that the use of PCM layers reduced inside air temperatures by as much as $2.4^{\circ} \mathrm{C}$ and reduced the difference between the minimum and maximum temperatures. Tokuç et al. [5] analyzed flat concrete roofs with PCM layers experimentally and numerically. They simulated the temporal variation of the solid-liquid phases of PCM layers of various thicknesses and reported that no PCM was suitable for all seasons of the year. They also found that a PCM whose phase change occurs at $27^{\circ} \mathrm{C}$ was ideal for use in intermediate seasons. Jayalath et al. [6] demonstrated that the thermal performance of a residential building could be improved by using a PCM layer on its roof to reduce cooling and heating loads and to improve thermal comfort. Chou et al. [7] proposed a new design for a metal sheet roofing structure with a PCM for use in residential houses. The proposed design consists of two layers of corrugated roofing, inside of which is a layer of PCM and a layer of polyurethane insulation. This roof design can reduce the downward heat flow through the roof, and as a result, indoor comfort can be maintained much longer than with typical roofing materials. Alqallaf 
and Alawadhi [8] performed a thermal analysis of a concrete roof with vertical cylindrical holes filled with a PCM and found that the heat gain was affected by the amount of PCM and its melting temperature. The proposed roof was found to reduce the cooling load by $17.26 \%$ in Kuwait City, Kuwait. Emulsions of PCM have also been used to reduce surface temperatures and mitigate urban heat island effects. Santamouris et al. [9] examined coatings developed with infrared reflective pigments doped with PCM. Chung and Park [10] proposed the use of PCM tiles covered with shape-stabilized PCM and demonstrated that the incident irradiation on a roof with a PCM layer can be utilized to reduce internal heat flow from the roof to mitigate the urban heat island effect. These studies, similar to most in the relevant literature, have investigated and advocated the integration of PCMs in roof layers. However, this approach is applicable only to new buildings, and buildings that are less than 10 years old account for only $8 \%$ of the total building stock in Seoul, Korea [18].

In this paper, a type of PCM thermal plate that can be installed on the roofs of existing buildings is proposed for use in dissipating heat. First, the proposed PCM thermal plate design is described. Next, the results of an assessment of the thermal performance of PCMs with different phase-change temperatures, conducted using a small-scale model, are discussed. The results of a dynamic building simulation, conducted to assess building energy consumption, are also presented. Finally, the results of an experimental application and assessment of the energy performance of the proposed PCM plate design on a flat roof are compared.

\section{Materials and Methods}

\subsection{Experimental Materials}

Roof materials can absorb energy from sunlight incident on buildings and convert it to sensible heat, thus intensifying the urban heat island effect. Reflective roofs can mitigate this effect and reduce cooling loads but may increase heating loads. In this paper, a roof material containing a PCM is proposed to offset the aforementioned heating penalty. In a previous study, PCM-doped tiles that could maintain low surface and chamber air temperatures during summer were developed, but these tiles had poor durability. This paper proposes the use of PCM packed in plastic bags (Figure 1) to increase the durability of the roof material. Liquefied PCM $(35 \mathrm{~g})$ is poured into nylon plastic bags and sealed through thermocompression bonding. The packing size was determined considering the size of the hollow of the WPC plate. Packing PCM into plastic bags was proposed by a colleague at Soongsil University. A type of PCM with a higher melting temperature was selected to reduce roof surface temperatures in summer. Roof surface temperatures can rise to up to $50{ }^{\circ} \mathrm{C}$ when outdoor temperatures reach approximately $30^{\circ} \mathrm{C}$ [19]. For that reason, PCMs with melting temperatures of $44^{\circ} \mathrm{C}$ and $25^{\circ} \mathrm{C}$ were selected for use in this study to compare their surface temperature reduction effects.

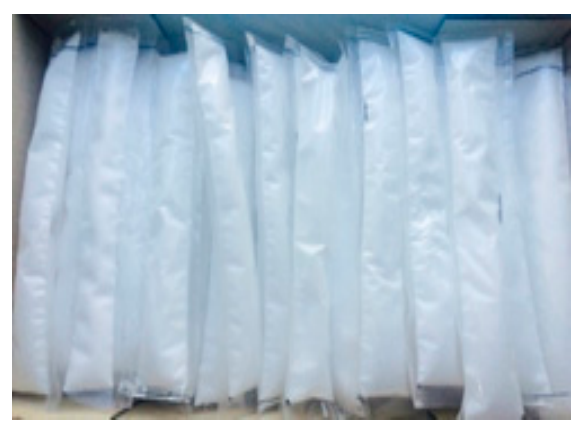

Figure 1. Packed phase-change material (PCM) in nylon plastic bags. 
The proposed thermal plate is composed of a wood-plastic composite (WPC), which is a hybrid material composed of natural wood and plastic fibers. WPCs are safe, sustainable, and durable and are increasingly being used in the construction of infrastructure components such as outdoor decks, park pathways, public benches, and sound-barrier walls along highways and railways [20,21]. In addition, WPCs have high structural strength, which compensates for the low strength of PCMs in the liquid phase. Packed PCMs were placed in the hollow sections of the WPC plate (Figure 2). The packed PCM was liquefied and inserted into the hollows.

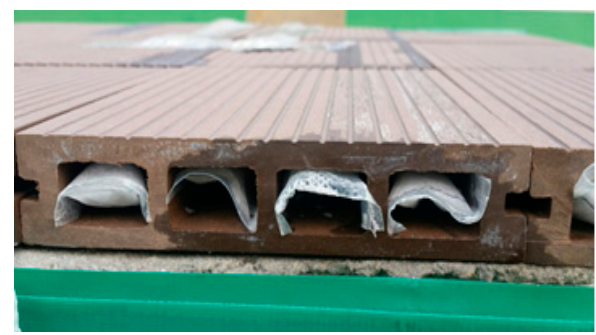

Figure 2. Packed PCM placed within the hollows of the wood-plastic composite (WPC) plate.

Because WPCs are composite materials composed of wood and plastic fibers, the surface temperatures of WPCs can rise higher than those of their wooden counterparts. The thermal properties of WPC plates greatly influence the heat flow to PCMs packed within and thus the phase of the PCMs. In this study, thermal conductivity was measured using a TCi thermal conductivity analyzer (C-THERM Technologies, Ltd., Seoul, Korea), and the averages of sets of 10 measurements are reported herein. The thermal conductivity of the WPC was $0.53 \mathrm{~W} /(\mathrm{m} \cdot \mathrm{K})$. The thermal conductivity of the WPC was slightly higher than that of a typical hardwood $(0.15 \mathrm{~W} /(\mathrm{m} \cdot \mathrm{K}))$ [22] and lower than that of concrete $(2.29 \mathrm{~W} /(\mathrm{m} \cdot \mathrm{K}))$.

\subsection{Experimental Setup}

The experiment was performed in Seoul, Korea, from 22 to 24 August and from 20 to 25 September 2015. Testing was performed on clear days in an external environment over the course of a week. Weather data were obtained from in-field measurements using an HD52-3DP17 Delta Ohm ultrasonic anemometer (Delta OHM, Seoul, Korea) that can measure the wind speed, wind direction, humidity, temperature, and solar radiation. The accuracy of wind speed, wind direction, air temperature, and humidity was $\pm 3 \%, \pm 2 \%, \pm 0.1 \%$, and $\pm 1.5 \%$, respectively. In addition, a second-class pyranometer was used for solar radiation. Cloud coverage data were obtained from the Korean meteorological administration.

An accurate scale model (approximately 1:10; $600 \mathrm{~mm} \times 600 \mathrm{~mm} \times 600 \mathrm{~mm}$ ) of the flat roof of an actual office building was built (Figures 3 and 4). The Table 1 listed the thermal conductivity and thickness of a roof used in this experiment. The concrete layer would have been reduced to a thickness of $25 \mathrm{~mm}$, but a layer thickness of $30 \mathrm{~mm}$ was selected on the basis of the aggregate size. If the layer thickness were $25 \mathrm{~mm}$, it would have been too thin and the layer would have been unable to develop adequate strength. The proposed thermal plate was fabricated and placed atop the roof. The walls and floor were built with thick insulation to minimize heat flow through them. Temperatures were measured at the center of the surface, within the inner hollows, at the bottom of the plate, and at the ceiling, using a t-type thermocouple and a GL820 data logger (Graphtec Corporation, Seoul, Korea). The thermocouples were affixed to each surface and covered with aluminum tape to assure good contact between the thermocouple and each surface. 


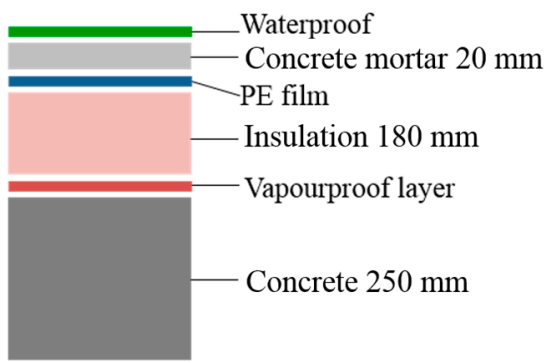

(a)

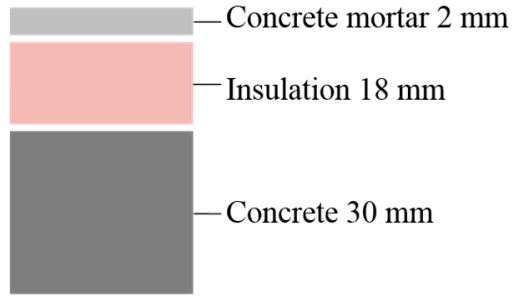

(b)

Figure 3. A 1:10 scale model of the flat roof of an actual office building. (a) Cross-section of the actual roof; (b) Cross-section of the scale model.

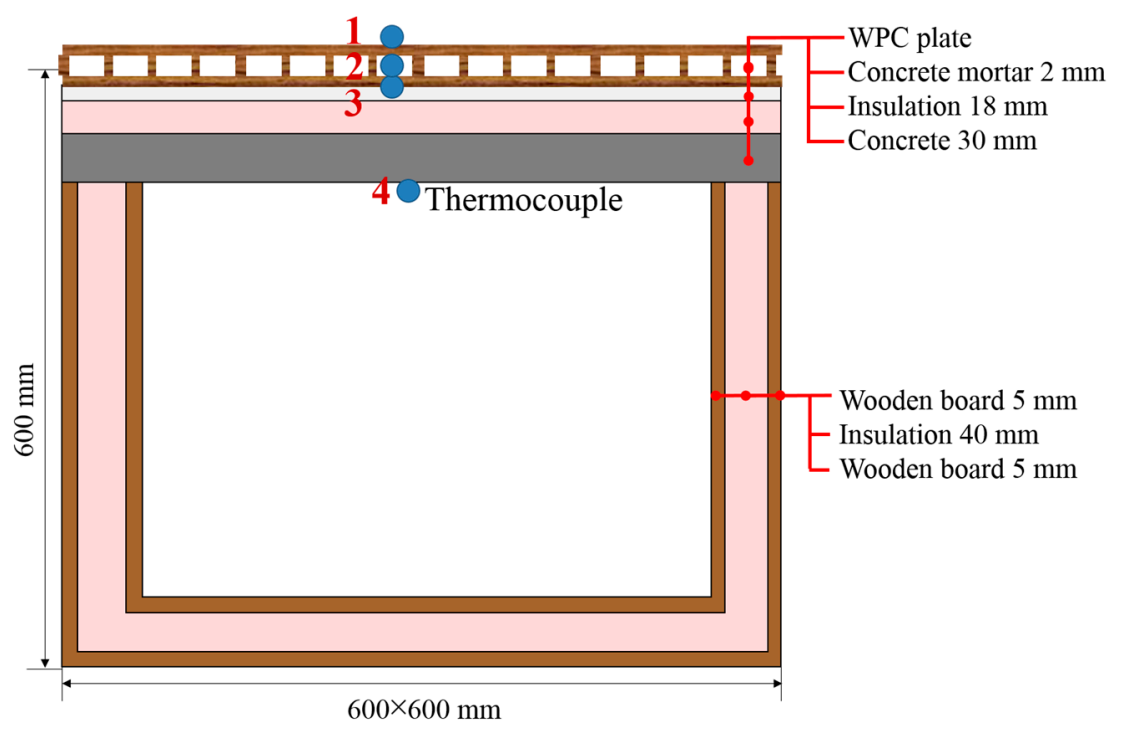

Figure 4. Dimensions of the scale model and the temperature measurement locations.

Table 1. Thermal conductivity of a roof.

\begin{tabular}{cccc}
\hline Materials & Thermal Conductivity $(\mathbf{W} /(\mathbf{m} \cdot \mathbf{K}))$ & Thickness $(\mathbf{m m})$ & Reference \\
\hline Concrete mortar & 0.58 & 2 & {$[23]$} \\
Insulation & 0.027 & 18 & {$[24]$} \\
Concrete & 2.29 & 30 & {$[25]$} \\
WPC & 0.53 & 5 (total height 30) & This work \\
\hline
\end{tabular}

Melting temperature was used as the measure of thermal performance. Two PCMs, one consisting of n-docosane and the other consisting of fatty acids, were used in the experiments. The two PCMs, referred to as RT 44 and RT 25, have melting temperatures of $44{ }^{\circ} \mathrm{C}$ and $25{ }^{\circ} \mathrm{C}$, respectively, and latent heats of fusion of approximately 241.3 and $200 \mathrm{~J} / \mathrm{g}$, respectively. The latent heat of RT 44 was checked using differential scanning calorimetry (DSC, Q1000) by a colleague at Soongsil University [26]. The latent heat of RT 25 was measured by Phase Change Material Solutions ${ }^{\mathrm{TM}}$ (Asheboro, NC, USA) [27]. Each PCM pack weighed $35 \mathrm{~g}\left(1166 \mathrm{~g} / \mathrm{m}^{2}\right)$. The small scale models are shown in Figure 5.

The albedos of the as-manufactured WPC thermal plate (with brown surface finishing) and a white-painted thermal plate were estimated using an albedometer according to ASTM E1918 [28] and were found to be 0.47 and 0.17 , respectively. The water-based paint (SUPRO ${ }^{\mathrm{TM}}, \mathrm{KCC}$ ) for commercial use was used in this study. For the scale model with white finishing, the PCM-layer temperatures of the thermal plates containing RT 44 and RT 25 were measured simultaneously. 


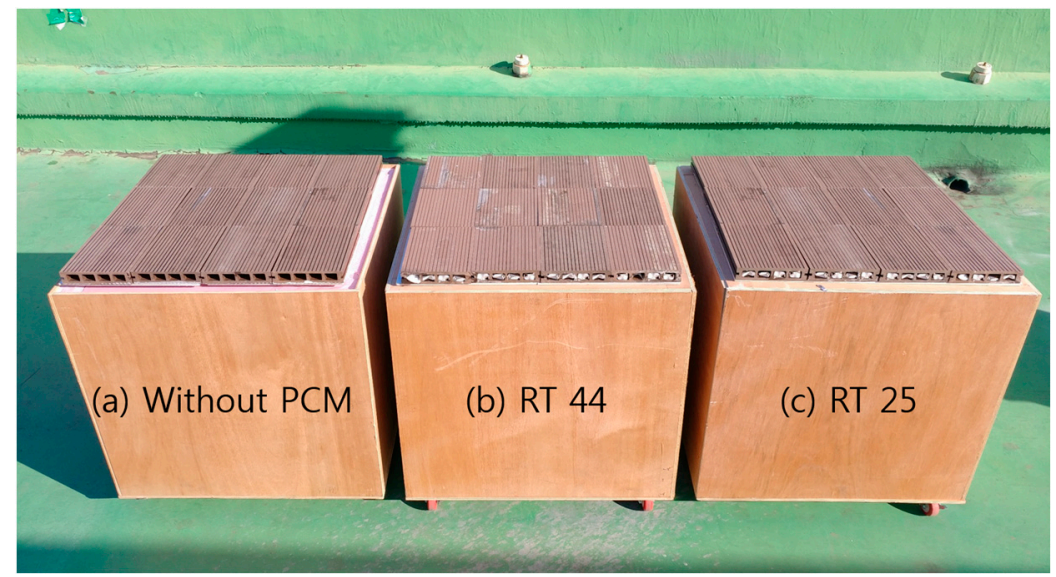

Figure 5. Small-scale models with as-manufactured WPC. (a) Without PCM; (b) Containing RT 44 in the hollows; and (c) With RT 25 in the hollows.

\subsection{Dynamic Building Simulation Setup}

A dynamic simulation of a full-scale building equipped with PCM thermal plates was conducted to verify the energy performance using the DesignBuilder dynamic thermal simulation software. The weather data used in the simulation were typical of a meteorological year in Seoul, Korea and were obtained from the Korean Solar Energy Society (Seoul, Korea) [29]. The building was modeled as a single story with an area of $160 \mathrm{~m}^{2}$, as shown in Figure 6 . The building was considered to be a single thermal zone. The envelope of the building consisted of external brickwork $(0.105 \mathrm{~m}$ thick), extruded polystyrene (XPS, $0.118 \mathrm{~m}$ thick), concrete block (0.100 $\mathrm{m}$ thick), and gypsum plastering (0.013 m thick), with an overall thermal transmittance of $0.250 \mathrm{~W} / \mathrm{m}^{2} \mathrm{~K}$. The floor consisted of urea formaldehyde foam $(0.240 \mathrm{~m}$ thick) cast concrete $(0.100 \mathrm{~m}$ thick), floor screed $(0.070 \mathrm{~m}$ thick $)$ and timber flooring $\left(0.030 \mathrm{~m}\right.$ thick), with an overall thermal transmittance of $0.150 \mathrm{~W} / \mathrm{m}^{2} \mathrm{~K}$. The roof consisted of an aerated concrete slab ( $0.080 \mathrm{~m}$ thick), expanded polystyrene $(0.140 \mathrm{~m}$ thick), concrete $(0.200 \mathrm{~m}$ thick), and plasterboard $\left(0.010 \mathrm{~m}\right.$ thick), with an overall thermal transmittance of $0.183 \mathrm{~W} / \mathrm{m}^{2} \mathrm{~K}$. The windows were modeled as double clear glass panes ( $3 \mathrm{~mm}$ glass $+6 \mathrm{~mm}$ air $+3 \mathrm{~mm}$ glass). The overall thermal transmittance was $2.440 \mathrm{~W} / \mathrm{m}^{2} \mathrm{~K}$, and the solar heat gain coefficient and visible transmittance were 0.595 and 0.769 , respectively. The window-to-wall ratios were $40 \%$ for the southern orientation and $30 \%$ for the eastern and western orientations.

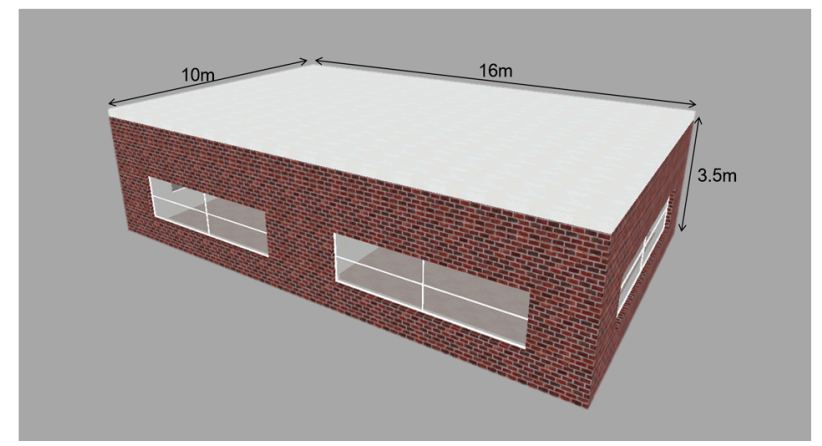

Figure 6. Description of a single-story building.

We assumed that the thermal plates were placed on the roof of the existing building, as shown in Figure 6. The PCM was modeled as the same material studied in small-scale experiments. For the n-docosane $\mathrm{PCM}$, with a melting temperature of $44^{\circ} \mathrm{C}$, or the fatty acids, with a melting temperature $25^{\circ} \mathrm{C}$, the thickness of PCM layer was $0.074 \mathrm{~m}$, and the thickness of the hard wood particle panels was 
$0.010 \mathrm{~m}$. The overall thermal transmittance of the roof with PCM thermal plate was $0.174 \mathrm{~W} / \mathrm{m}^{2} \mathrm{~K}$. The roof solar reflectance applied to the same value, 0.47 for as-manufactured WPC and 0.17 for white painted roof, as those used in the experiment.

\section{Results and Discussion}

\subsection{Results with Respect to the Melting Temperature of the Phase-Change Material}

Experimental measurements were performed on 22-24 August. The average air temperatures on these three days were $23.9^{\circ} \mathrm{C}, 22.0^{\circ} \mathrm{C}$ and $23.4{ }^{\circ} \mathrm{C}$, respectively, and the average wind speeds were 1.8 , 1.7 and $1.9 \mathrm{~m} / \mathrm{s}$, respectively. The cloud covers were $0.5,6.6$ and 3.0, respectively. Further, 23 August was a cloudy day; hence, comprehensive experimental analyses were conducted on 24 August. The accumulated solar irradiation was $4632 \mathrm{Wh} / \mathrm{m}^{2}$, which is higher than the average summer solar irradiation of $3709 \mathrm{Wh} / \mathrm{m}^{2}$ [10].

The surface temperature of the WPC plate without the PCM increased to $54.5^{\circ} \mathrm{C}$, that of the plate with RT 25 increased to $52.2^{\circ} \mathrm{C}$, and that of the plate with RT 44 increased to $47.7^{\circ} \mathrm{C}$ (Figure 7). The fact that the surface temperature was the highest on the plate without the PCM is evidence that PCMs can reduce the peak daytime surface temperatures of building roofs. The PCM can store the heat from the sun during daytime and thereby reduce the peak surface temperature. The degradation temperature varied with the melting temperature of the PCM. Typically, PCM layers are installed inside buildings; hence, the PCMs used in this study were chosen on the basis of indoor air temperatures. For PCM layers in thermal plates installed on the exterior of a building, the PCM with the higher melting temperature was found to be more efficient in reducing the surface temperature. After the phase change to liquid, the PCM temperature increased with the sensible heat. When the surface temperature decreased after sunset, RT 25 cooled more rapidly that RT 44 during its early cooling phase because only its sensible heat was involved. After solidification, the temperature of RT 44 was lower than that of RT 25 and was similar to that of the plate without PCM. After sunset, RT 44 was solidified immediately and exhibited sensible heat changes, but RT 25 was solidified at night, as shown in Figure 8. Therefore, the surface temperature of RT 25 was higher than that of RT 44 at midnight. Furthermore, the day-night temperature difference varied with the melting temperature of the PCM: RT 44 exhibited the smallest temperature difference, followed by RT 25, and the plate without PCM.

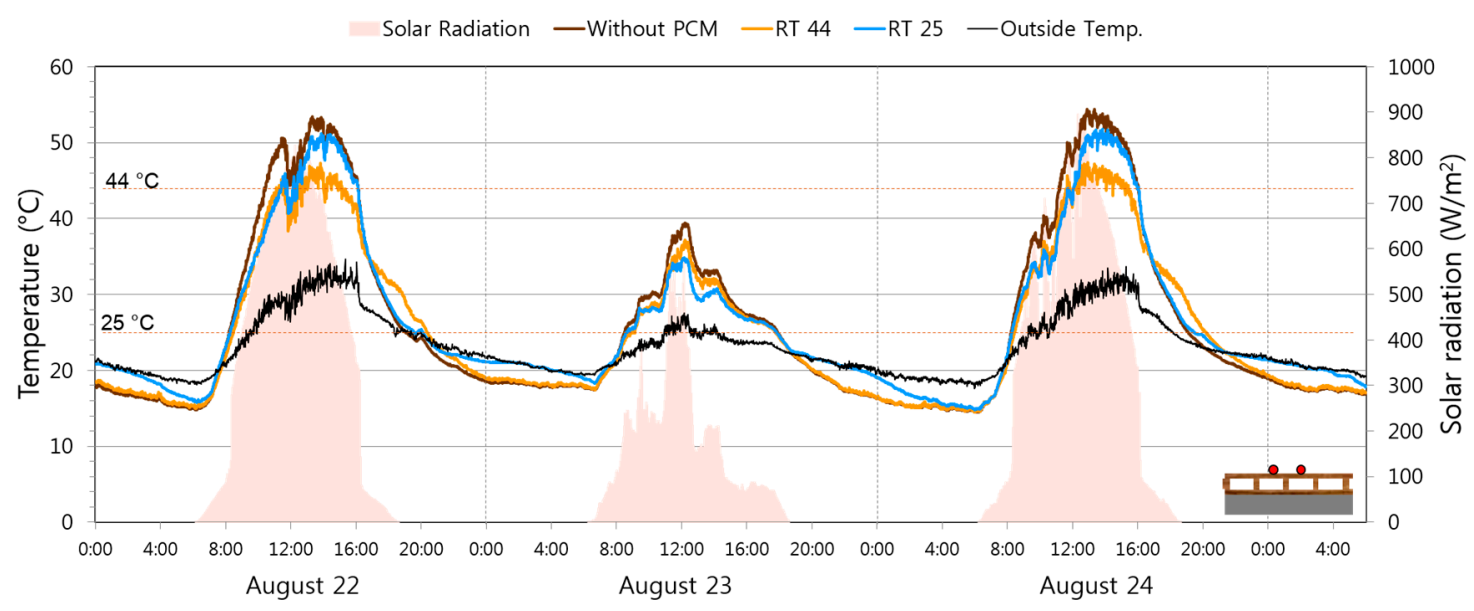

Figure 7. Outer surface temperatures of the plates with PCMs with different melting temperatures. 


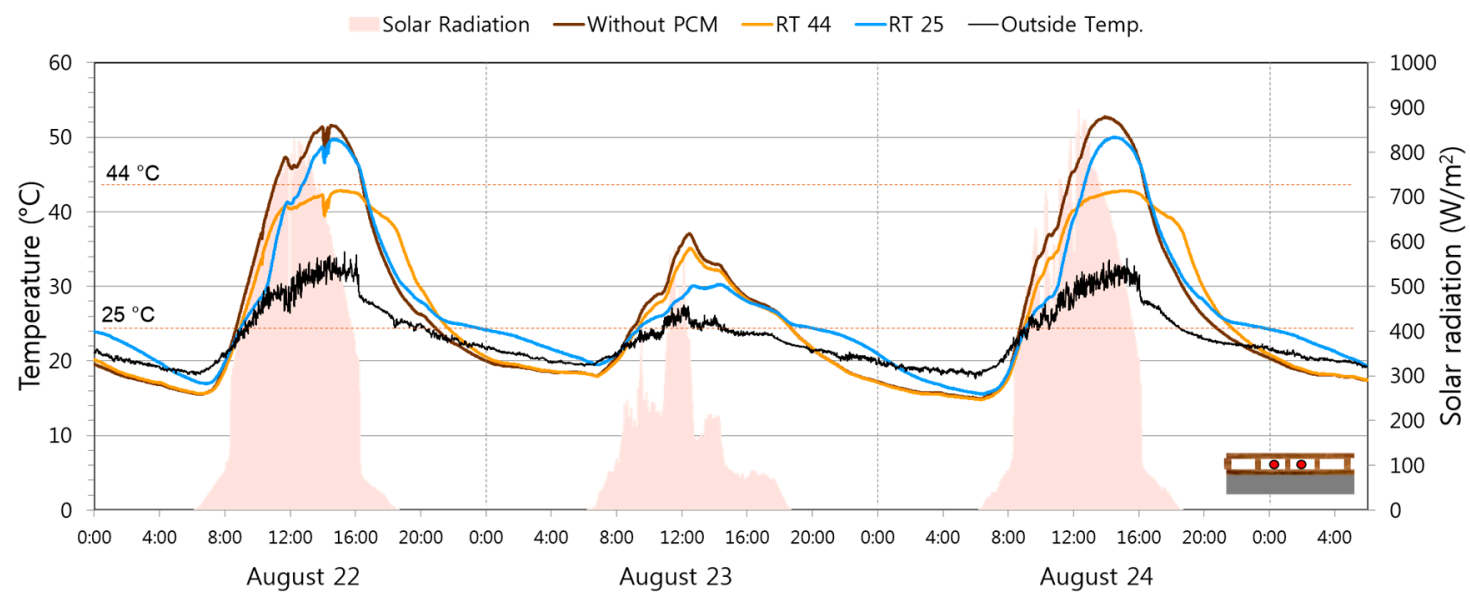

Figure 8. Hollow temperature of the plates with PCMs with different melting temperatures.

Temperature measurement in the inner hollows was performed with the probe in contact with the packed PCM; the results are plotted in Figure 8. The highest temperature was recorded on 24 August on the plate without the PCM $\left(54.5^{\circ} \mathrm{C}\right)$, followed by the plate with RT $25\left(50.1^{\circ} \mathrm{C}\right)$ and that with RT 44 $\left(43.2^{\circ} \mathrm{C}\right)$. The peak of the internal temperature lagged behind that of the surface temperature by $1-1.5 \mathrm{~h}$. In the plate with RT 44, the inner temperature was stabilized near the phase-change temperature; the heat was stored as latent heat and was not converted to sensible heat. In contrast, in the plate with RT 25, the temperature continued to increase beyond the phase-change temperature, and hence the heat was stored as sensible heat. During the cooling phase, in the case of RT 25, the difference between the inner temperature and the ambient temperature was initially large, but when the phase changed to solid, the difference was small; thus, the temperature stabilized around the phase-change temperature. Consequently, the nighttime temperature of RT 25 was higher than those of the other PCMs.

The temperature of RT 44 on 23 August was exceeded by that of RT 25. On 23 August, the day was cloudy, so there was less solar radiation than on the other days. The temperature of the inner hollows did not reach the phase-change temperature of $44^{\circ} \mathrm{C}$. RT 44 did not experience a phase change, but RT 25 did. This means that RT 44 stored sensible heat during the daytime, whereas RT 25 stored heat as latent heat and then as sensible heat. The temperature of RT 44 was higher than that of RT 25 . Therefore, the temperature of RT 44 was exceeded by that of RT 25 on cloudy days.

The temperature measurements taken at the bottom of the plate are presented in Figure 9. The temperature trend was similar to that of the hollows. The plate without the PCM exhibited the highest temperature $\left(48^{\circ} \mathrm{C}\right)$, followed by that with RT $25\left(45^{\circ} \mathrm{C}\right)$ and that with RT $44\left(42{ }^{\circ} \mathrm{C}\right)$.

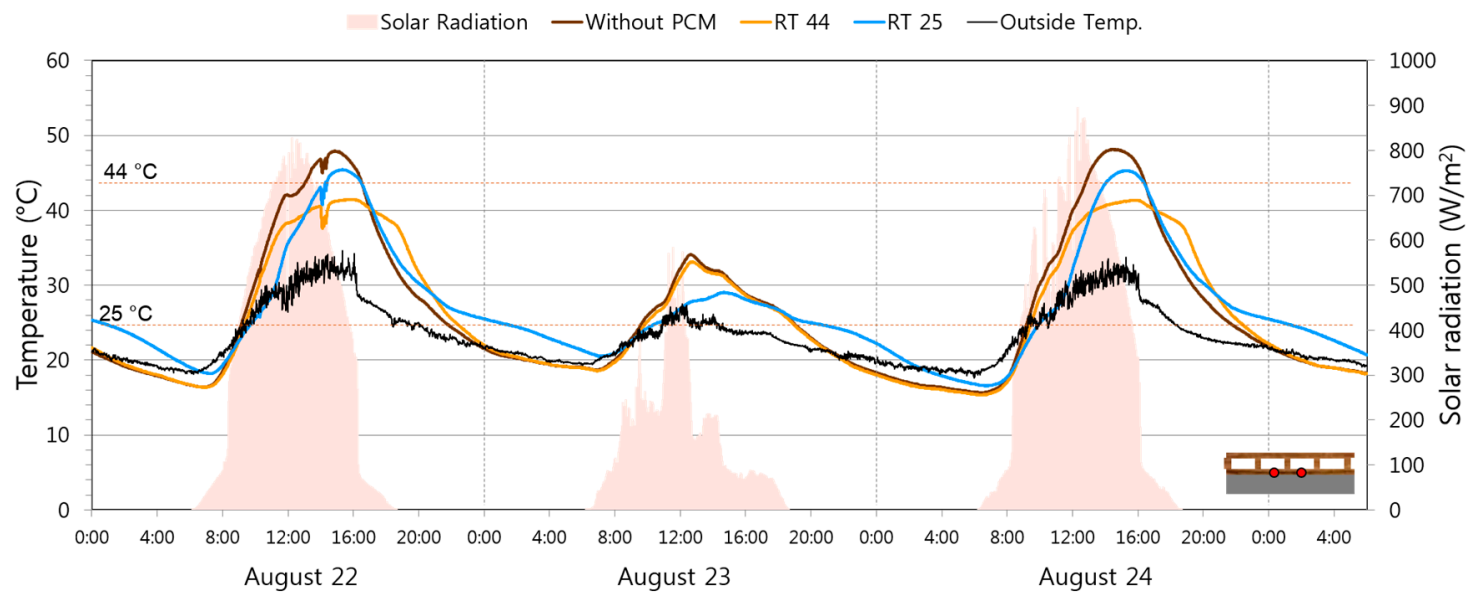

Figure 9. Bottom temperature of the plates with PCMs with different melting temperatures. 
The corresponding temperature measurements for the chamber ceiling are shown in Figure 10. The maximum temperature was recorded on the plate without PCM $\left(38^{\circ} \mathrm{C}\right.$ at $4: 40$ p.m.), followed by the plate with RT $25\left(36.5^{\circ} \mathrm{C}\right.$ at 5:20 p.m.) and that with RT $44\left(35.6^{\circ} \mathrm{C}\right.$ at 5:31 p.m.). The indoor temperature range was the narrowest for the plate with RT 44, followed by that with RT 25 and that without the PCM. These results confirm that using a PCM in a roof can reduce the indoor temperature fluctuation range. Furthermore, the use of a PCM can delay the time of day at which the peak temperature occurs, which can reduce the peak energy load and improve indoor thermal comfort.

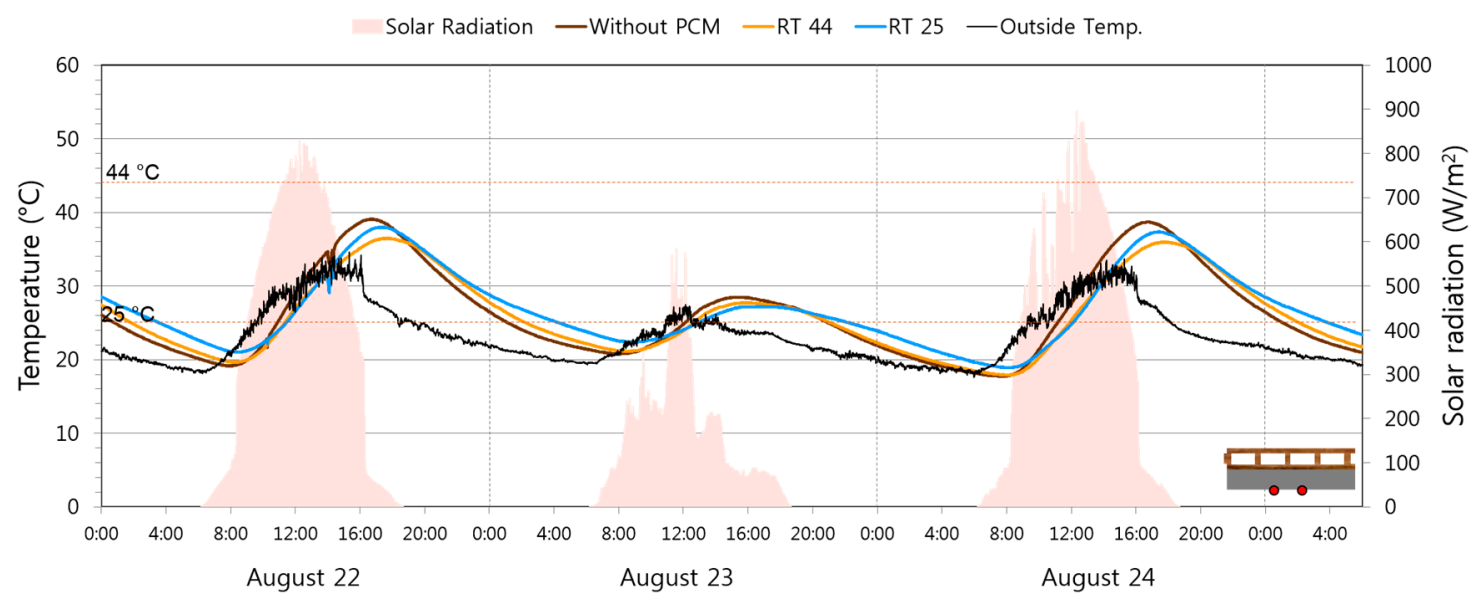

Figure 10. Chamber ceiling temperature in the plates with PCMs with different melting temperatures.

\subsection{Results with Respect to Surface Finishing Color}

The effect of the surface finishing color on the thermal performance of the three scale models-namely, the models with RT 44 and brown finishing, RT 44 and white finishing, and RT 25 and white finishing - was examined during the period of 20-25 September. The results are presented in Figure 11. The average air temperatures on these days were $18.8^{\circ} \mathrm{C}, 17.9^{\circ} \mathrm{C}, 17.5^{\circ} \mathrm{C}, 17.5^{\circ} \mathrm{C}, 16.9{ }^{\circ} \mathrm{C}$ and $16.3^{\circ} \mathrm{C}$. The average wind speeds were 1.6, 1.6, 2.2, 2.4, 2.5 and $2.1 \mathrm{~m} / \mathrm{s}$. The cloud covers were $2.9,0.0,2.1,6.1,4.4$ and 2.1, respectively. Detailed analyses were conducted on Day 6, on which the accumulated solar irradiation of $3339 \mathrm{Wh} / \mathrm{m}^{2}$ was similar to the average summer solar irradiation of $3709 \mathrm{Wh} / \mathrm{m}^{2}$ in Korea [10].

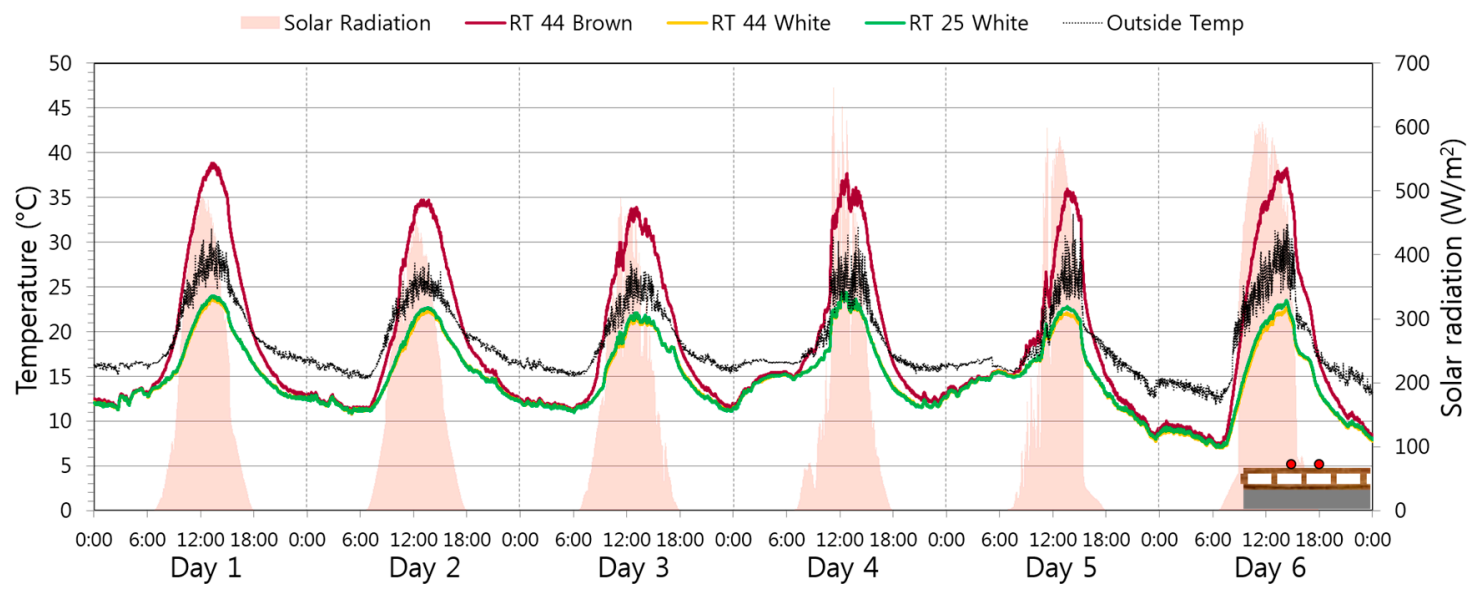

Figure 11. Variation in outer surface temperature with finishing color and PCM.

When the highest temperature in the model with RT 44 and brown finishing, $39^{\circ} \mathrm{C}$, was recorded, the temperature of the model with RT 44 and white finishing was $23^{\circ} \mathrm{C}$. The reason for this was that the 
high albedo of the white surface reduced solar irradiation through the roof. The melting temperature did not appear to affect the thermal performance of the investigated PCMs with white finishing.

The corresponding results for the internal temperature on the same day are shown in Figure 12 The maximum temperature of the packed PCMs with brown finishing was $38^{\circ} \mathrm{C}$, but this temperature was maintained for only a moment; hence, RT 44 did not liquefy completely. The thermal performance of RT 44 and RT 25 was nearly the same: the maximum temperature was approximately $23^{\circ} \mathrm{C}$ in both cases, and hence neither of the PCMs liquefied, because the increased albedo reduced the solar irradiation. Neither of the plates of the PCMs reached the phase-change temperature. Therefore, the temperatures of the two types of PCM exhibited similar trends. During nighttime, the lowest temperature was $7^{\circ} \mathrm{C}$, and there was no difference in melting temperatures between the finishing colors. Furthermore, the diurnal temperature variation of the models with white finishing was more gradual than that of the model with brown finishing.

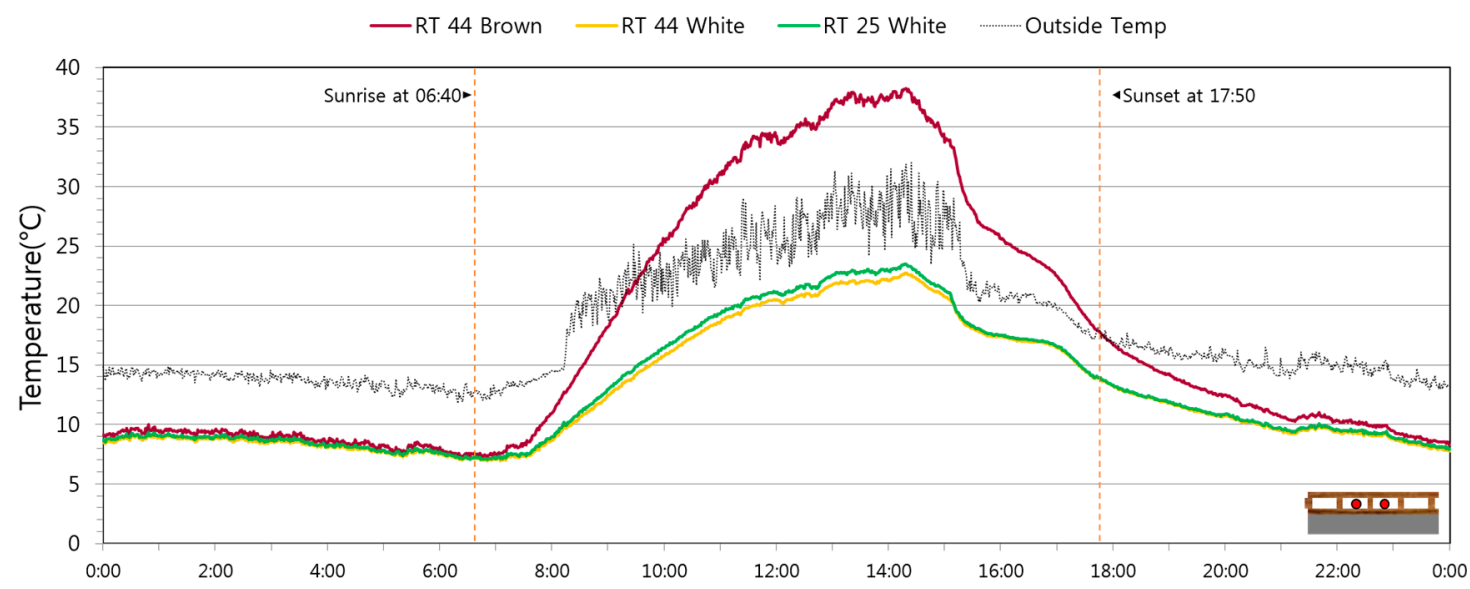

Figure 12. Variation in hollow temperature with finishing color and PCM.

The maximum chamber ceiling temperature of RT 44 with brown finishing was $29^{\circ} \mathrm{C}$ (Figure 13), while that of both RT 44 and RT 25 with white finishing was approximately $23^{\circ} \mathrm{C}$. The temperature peaked nearly simultaneously for all models. These results suggest that using a finishing color with a high albedo can reduce the inside temperature [30].

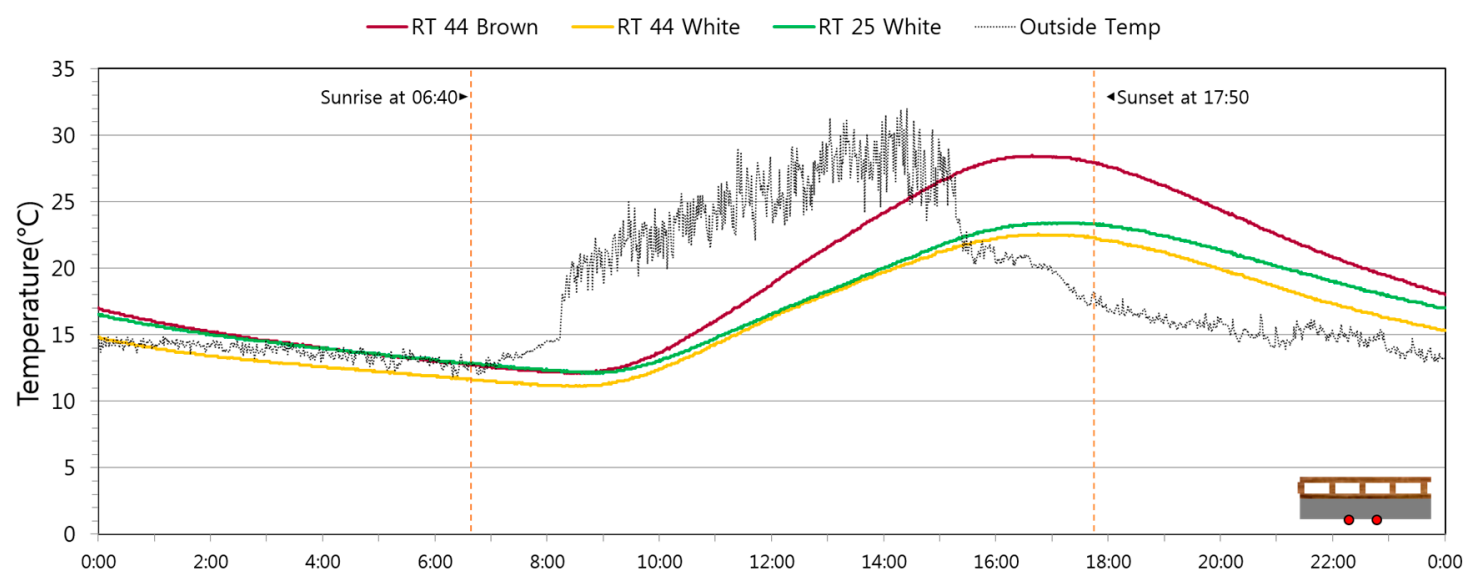

Figure 13. Variation in chamber ceiling temperature with finishing color and PCM. 


\subsection{Results of Dynamic Building Simulation}

The roof surface temperature and building energy consumption were estimated for summer conditions. A simulation was also conducted to assess the thermal performance for winter conditions. The roof surface temperatures by roof finishing types in summer and winter were compared. As Figure 14 shows, the range of roof surface temperatures was narrower in both summer and winter when the PCM thermal plates were installed. The peak difference in the surface temperature with the existing roof and PCM thermal plates with RT 25 and RT 44 was approximately $3.1{ }^{\circ} \mathrm{C}$ and $7.7^{\circ} \mathrm{C}$, respectively, on a typical summer day. Similarly to an experiment, the surface temperature of covering a white-painted roof with RT 25 is similar to that of RT 44. That surface temperature was almost $17^{\circ} \mathrm{C}$ lower than that of the existing roof. This means that the albedo of the roof has a reduction effect on the surface temperature. In summer, maintaining a lower surface temperature can help to improve indoor thermal comfort [31]. In winter, the PCM roof surface temperature with RT 25 and RT 44 was approximately $0.4-1.1^{\circ} \mathrm{C}$ lower than the existing roof temperature, but the PCM roof remained warmer than the existing roof at night. This improved the thermal comfort and reduced the heating energy required at night. However, the roof temperature of white-painted PCM thermal plates was the lowest during daytime. This might cause a heating penalty in winter. Therefore, covering a white-painted roof finishing should be done carefully and should consider cooling energy savings and the heating penalty.

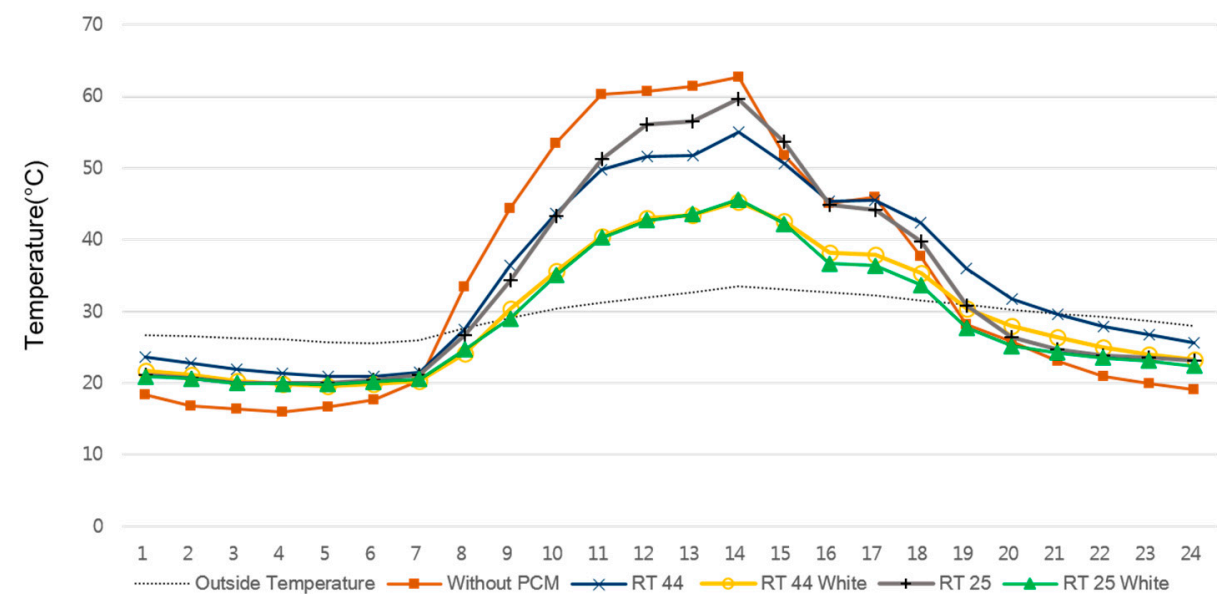

(a)

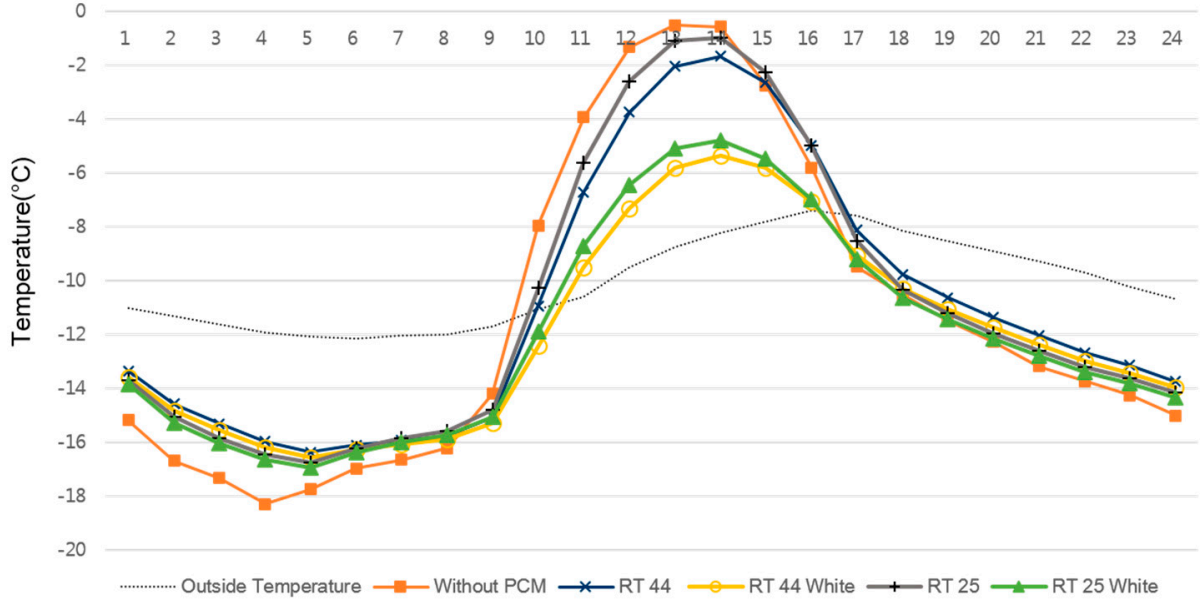

(b)

Figure 14. Roof surface temperature. (a) A typical summer day; (b) A typical winter day. 
The placement of the PCM layer plays an important role in the PCM layer's effectiveness in reducing the building energy consumption. Han and Talyor [32] found that an inner PCM layer was most effective in reducing the building energy consumption. However, this applies to a PCM with a melting temperature of approximately $25^{\circ} \mathrm{C}$. The melting temperature is an important factor in the selection of a PCM. In this study, PCMs were installed in the external layer of an existing building roof. Han and Talyor [32] also found that the placement of a PCM in an outer layer could reduce both the heating and cooling energy consumption. Therefore, in this study, we decided to place the PCMs within an external roof layer.

Figure 15 shows the monthly energy consumption by roof finishing types. The annual energy consumption of a building without a PCM roof layer was calculated to be $181 \mathrm{kWh} / \mathrm{m}^{2}$, and that of a building with a PCM installation was calculated to be $166-168 \mathrm{kWh} / \mathrm{m}^{2}$. Energy simulation results suggest that a roof with a PCM thermal plate can reduce the annual energy consumption by $7 \% \sim 8 \%$ regardless of the melting temperature. Adding a PCM layer can improve the thermal transmittance of roof layers. Our simulation results suggest that a roof with a PCM thermal plate consumes $20 \%$ less heating energy and $2 \%-3 \%$ less cooling energy. There was a slight energy consumption difference between the melting temperature of the PCM and the roof surface albedo. A PCM thermal plate can reduce the surface temperature of a roof, but the reduction in cooling energy achieved is lower than expected. A PCM with a thermal plate can retain heat during daytime and can emit heat during nighttime. Therefore, the temperature of a PCM thermal plate can remain lower, but there is a smaller effect on the cooling energy consumption. Saving cooling energy by covering a roof with a higher albedo is similar to a heating penalty.

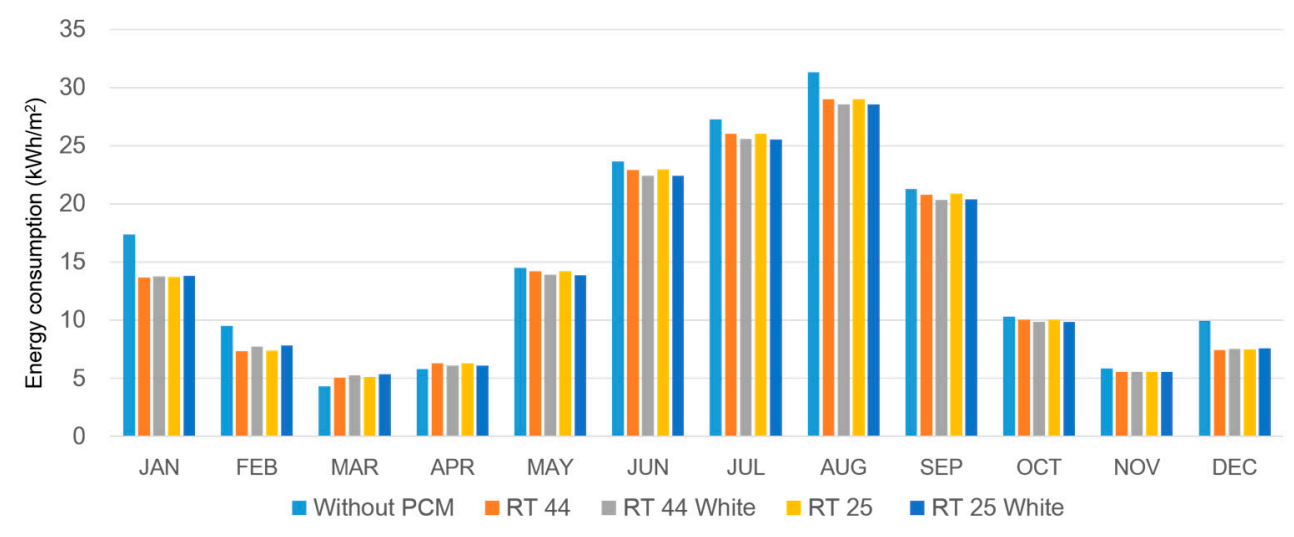

Figure 15. Monthly energy consumption by roof finishing types.

\section{Conclusions}

The thermal performance of PCM thermal plates as roof finishing materials, which have been proposed to improve the thermal performance of buildings, was evaluated in this study. PCM plates can be fabricated from WPCs and easily installed on existing buildings. The thermal performance of PCM plates with two different melting temperatures and WPC finishing colors was examined. PCMs with high melting temperatures were used because the PCMs were placed on building roofs. In a previous study [10], the PCM-doped tiles were proposed to reduce the surface temperature. In that case, the PCM was lost during liquefaction and the solidification phase. The PCMs were packed in nylon plastic bags to prevent PCM loss during phase changes, thereby improving their durability compared to the previous work.

Thermal plates with PCMs exhibited lower surface temperatures than those without PCMs. The PCM with a melting temperature of $44{ }^{\circ} \mathrm{C}$ was able to maintain a relatively constant indoor temperature, as compared to the PCM with a melting temperature of $25^{\circ} \mathrm{C}$. The onset of the peak temperature in the chamber was delayed the most when a PCM was installed. Therefore, a PCM with 
a high phase-change temperature is ideal during summer. As expected, the temperatures in various layers of the plates with white surface finishings were lower than those in the plates with the original brown finishings. Furthermore, the annual energy difference by finishing albedo was less because the heating penalty was similar to the cooling energy saving. The results suggest that using high-albedo finishing materials with a PCM could reduce both the roof surface temperature and energy consumption.

The potential for reducing the surface temperatures of roofs with PCMS was evaluated in this study. PCM thermal plates were demonstrated to be beneficial in reducing surface and chamber temperatures. Furthermore, PCM plates made diurnal temperature variations more gradual, thereby contributing to thermal comfort. The experiments in this study were conducted in August and September. The experiment was carried out owing to the quantity limit of models. Future studies will focus on the evaluation of the thermal performance of these plates during winter and summer.

Acknowledgments: This research was supported by the Basic Science Research Program through the National Research Foundation of Korea (NRF), funded by the Ministry of Science, Information and Communications Technologies (ICT) and Future Planning (2014R1A1A1004131). This is research was supported by a grant (16CTAP-C078014-03) from the Infrastructure and transportation technology promotion research program funded by the Ministry of Land, Infrastructure and Transport of Korean government.

Author Contributions: Min Hee Chung designed the experiments and analyzed the data. Jin Chul Park was involved in writing the manuscript and discussing the results.

Conflicts of Interest: The authors declare no conflict of interest.

\section{References}

1. Wang, X.; Yu, H.; Li, L.; Zhao, M. Experimental assessment on the use of phase change materials (PCMs)-bricks in the exterior wall of a full-scale room. Energy Conv. Manag. 2016, 120, 81-89. [CrossRef]

2. Kara, Y.A. Diurnal performance analysis of phase change material walls. Appl. Therm. Eng. 2016, 102, 1-8. [CrossRef]

3. Lee, K.O.; Medina, M.A.; Raith, E.; Sun, X. Assessing the integration of a thin phase change material (PCM) layer in a residential building wall for heat transfer reduction and management. Appl. Energy 2015, 137, 669-706. [CrossRef]

4. Guichard, S.; Miranville, F.; Bigot, D.; Boyer, H. A thermal model for phase change materials in a building roof for a tropical and humid climate: Model description and elements of validation. Energy Build. 2014, 70 , 71-80. [CrossRef]

5. Tokuç, A.; Başaran, T.; Yesügey, C. An experimental and numerical investigation on the use of phase change materials in building elements: The case of a flat roof in Istanbul. Energy Build. 2015, 102, 91-104.

6. Jayalath, A.; Aye, L.; Mendis, P.; Ngo, T. Effects of phase change material roof layers on thermal performance of a residential building in Melbourne and Sydney. Energy Build. 2016, 121, 152-158. [CrossRef]

7. Chou, H.M.; Chen, C.R.; Nguyen, V.L. A new design of metal-sheet cool roof using PCM. Energy Build. 2013, 57, 42-50. [CrossRef]

8. Alqallaf, H.J.; Alawadhi, E.M. Concrete roof with cylindrical holes containing PCM to reduce the heat gain. Energy Build. 2013, 61, 73-80. [CrossRef]

9. Santamouris, M.; Synnefa, A.; Karlessi, T. Using advanced cool materials in the urban built environment to mitigate heat islands and improve thermal comfort conditions. Sol. Energy 2011, 85, 3085-3102. [CrossRef]

10. Chung, M.H.; Park, J.C. Development of PCM cool roof system to control urban heat island considering temperate climatic conditions. Energy Build. 2016, 116, 341-348. [CrossRef]

11. Xiang, Y.; Zhou, G. Thermal performance of a window-based cooling unit using phase change materials combined with night ventilation. Energy Build. 2015, 108, 267-278. [CrossRef]

12. Li, D.; Ma, T.; Liu, C.; Zheng, Y.; Wang, Z.; Liu, X. Thermal performance of a PCM-filled double glazing unit with different optical properties of phase change material. Energy Build. 2016, 119, 143-152. [CrossRef]

13. Zhong, K.; Li, S.; Sun, G.; Li, S.; Zhang, X. Simulation study on dynamic heat transfer performance of PCM-filled glass window with different thermophysical parameters of phase change material. Energy Build. 2015, 106, 87-95. [CrossRef]

14. Jin, X.; Zhang, X. Thermal analysis of a double layer phase change material floor. Appl. Therm. Eng. 2011, 31, 1576-1581. [CrossRef] 
15. Entrop, A.G.; Brouwers, H.J.H.; Reinders, A.H.M.E. Experimental research on the use of micro-encapsulated Phase Change Materials to store solar energy in concrete floors and to save energy in Dutch houses. Sol. Energy 2011, 85, 1007-1020. [CrossRef]

16. Huang, K.; Feng, G.; Zhang, J. Experimental and numerical study on phase change material floor in solar water heating system with a new design. Sol. Energy 2014, 105, 126-138. [CrossRef]

17. Belmonte, J.F.; Eguía, P.; Molina, A.E.; Almendros-Ibáñez, J.A. Thermal simulation and system optimization of a chilled ceiling coupled with a floor containing a phase change material (PCM). Sustain. Cities Soc. 2015, 14, 154-170. [CrossRef]

18. Korean Statistical Information Service. Available online: http://kosis.kr (accessed on 16 July 2015).

19. Pisello, A.L.; Rossi, R.; Cotana, R. Summer and winter effect of innovative cool roof tiles on the dynamic thermal behavior of buildings. Energies 2014, 7, 2342-2361. [CrossRef]

20. Morrell, J.J.; Stark, N.M.; Pendleton, D.E.; McDonald, A.G. Durability of wood-plastic composites. Wood Des. Focus 2006, 16, 7-10.

21. Markarian, J. Wood-plastic composites: Current trends in materials and processing. Plast. Add. Compd. 2005, 7, 20-26. [CrossRef]

22. Seo, J. An Analysis of Thermal Characteristics of Wood-Based Building Materials and Thermal Conductivity Database Construction. Ph.D. Thesis, Soongsil Universtiy, Seoul, Korea, 2015.

23. $\mathrm{Xu}, \mathrm{Y}$.; Chung, D.D.L. Effect of sand addition on the specific heat and thermal conductivity of cement. Cem. Concr. Res. 2000, 30, 59-61. [CrossRef]

24. Bouk Group (Insulation Company). Available online: http://www.bwxps.com/product/xps.html (accessed on 29 December 2016).

25. Kim, K.H.; Jeon, S.E.; Kim, J.K.; Yang, S. An experimental study on thermal conductivity of concrete. Cem. Concr. Res. 2003, 33, 363-371. [CrossRef]

26. Chang, S.J.; Wi, S.; Jeong, S.G.; Kim, S. Thermal performance evaluation of macro-packed phase change materials (PCMs) using heat transfer analysis device. Energy Build. 2016, 117, 120-127. [CrossRef]

27. Phase Change Energy Solutions. Available online: http://www.phasechange.com/ (accessed on 10 September 2016).

28. ASTM E 1918-06; Standard Test Method for Measuring Solar Reflectance of Horizontal and Low-Sloped Surfaces in the Field; ASTM International: West Conshohocken, PA, USA, 2006.

29. The Korean Solar Energy Society. Typical Weather Data for Korea, Seoul, No. 2010-Seoul-R-006; The Korean Solar Energy Society: Seoul, Korea, 2010.

30. Stavrakakisa, G.M.; Androutsopoulosb, A.V.; Vyörykkäc, J. Experimental and numerical assessment of cool-roof impact on thermal and energy performance of a school building in Greece. Energy Build. 2016, 130, 64-84. [CrossRef]

31. Lu, S.; Chen, Y.; Liu, S.; Kong, X. Experimental research on a novel energy efficiency roof coupled with PCM and cool materials. Energy Build. 2016, 127, 159-169. [CrossRef]

32. Han, Y.; Talyor, J.E. Simulating the inter-building effect on energy consumption from embedding phase change materials in building envelopes. Sustain. Cities Soc. 2016, 27, 287-295. [CrossRef]

(c) 2017 by the authors; licensee MDPI, Basel, Switzerland. This article is an open access article distributed under the terms and conditions of the Creative Commons Attribution (CC BY) license (http:/ / creativecommons.org/licenses/by/4.0/). 